\title{
Investigation on Skills of Greening Transformation for Existing College Campus Architecture in Jiangsu Province
}

\author{
Minghui LI',a, Yongqua FU², b ,Yongsheng SONG, Sheng QIAN, Yuping CHEN \\ ( Jinling Institute of Technology,Nanjing,Jiangsu 211169 China )
}

${ }^{1}$ Minhhui LI(1960- ), female, born in Cangzhou, Hebei Province, a professor from Jinling Institute of Technology, corresponding author, mainly works on green building research.

${ }^{2}$ Yongquan FU (1994- ), male, born in Xuzhou, Jiangsu Province, is a student from Jinling Institute of Technology.

aE-mail address: Imh@jlt.edu.cn;bE-mail:1277651037@qq.com

Key words: colleges in Jiangsu province, campus architecture, greening transformation, BIM technology

Abstract.According to the research and field tests on campus architecture in Jiangsu province, whic $\mathrm{h}$ indicates the current situations and problems existing in college buildings, this paper tries to put forward several skills on greening transformation which are based on the principles of green ization and local conditions to create green campuses, working for providing reference for the plan of greening transformation for existing college campus architecture in Jiangsu province.

\section{Introduction}

It is found that the number of the existing building stocks is quite big, except the newly-built campuses, a lot of buildings were established in early times. Problems also exist in these early buildings, such as the large consumption of resources and energy and low efficiency in operation. According to some related data, campus buildings have been large consumers of social resources.

In order to push forward green campus construction and realize sustainable development, those buildings with high energy consumption must be reformed. This paper mainly studies the skills on greening transformation for existing college buildings.

\section{General Characteristics of Energy Consumption in College Buildings}

Green campus refers to one which saves resources (including energy, water, raw materials, and land) and gets most out of them during the life circle. It helps protect environment and reduce pollution, providing healthy, suitable and efficient teaching and living environment for teachers and students.

It has the function of environmental education itself and keeps a harmonious co-existence with the environment. ${ }^{(1)}$ There are various kinds of campus architecture, such as teaching buildings, laboratory buildings, libraries, office buildings, gyms, canteens and so on. Most of them are public buildings, and they have the following characteristic of energy consumption:

(1) The bigger building size is, the higher energy-consuming occurs. The buildings have diverse levels and changing trends on energy consumption as different buildings have different functions. They need to be analyzed depending on specific cases. 
(2) Resulting from summer and winter vacations, energy consuming is volatile. Every February, July and August is a period with low usage of teaching buildings. For the rest of the year, high frequency in daytime brings high energy consuming.

(3) As lots of students use the buildings at the same time, lighting and temperature energy consume much as well as water resource.

\section{Skills of Greening Transformation Applied to Existing College Buildings in Jiangsu Province}

There are various kinds of college buildings in Jiangsu province, and with different functions, the energy consumption is different. The skills should be selected by specific cases. The following skills are commonly used.

\section{Application of BIM Technology}

Greening transformation based on BIM technology mainly focuses on the management and application of air-conditioning systems, heating systems, lighting systems and renewable energy system. ${ }^{2}$

\section{Application of BIM Technology in the Design Stage}

The process of building reconstruction is restricted by many factors, such as surroundings and population. BIM modeling with visualization technology and simulation function, make an important basis for the final decision.

\section{Application of BIM Technology in Practice}

Setting the number of indoor personnel, degrees of human activities, executing time of active system and simulating for thermal environment through BIM technology can be used to calculate hourly temperature, hourly heat gain and loss, monthly cooling and heating load, solar heat gain, ventilation heat gain, yearly temperature distribution, etc.

As the orientation of campus buildings has been fixed, solar radiation data from every direction can be collected through Weather Tool, and it can be used for non-equilibrium insulation design of building envelopes. An economical plan which meets the requirements of energy- saving can be achieved by setting integrated unit price of model materials, yearly maintenance costs and service life through BIM technology when comparing different plans.

The depth of college buildings is usually designed long to add the area of windows for natural lightning. However, according to the field test of buildings, improving the daylight effects by adding the area of windows doesn't get ideal effects. Take a teaching building with inner corridor as an example, a room which is $12.4 \mathrm{~m}$ wide, $8 \mathrm{~m}$ deep with the inner corridor $3 \mathrm{~m}$ wide is selected. Before reconstruction, the area of windows is $28.52 \mathrm{~m}^{2}$, accounting for $57.5 \%$ of facade space. Put a reflector $2.1 \mathrm{~m}$ above the earth. Comparing the before-and-after degrees of natural lighting, it turns out that the degree of inner lighting increases $10 \%$. The result of analysis is shown in fig.1. 


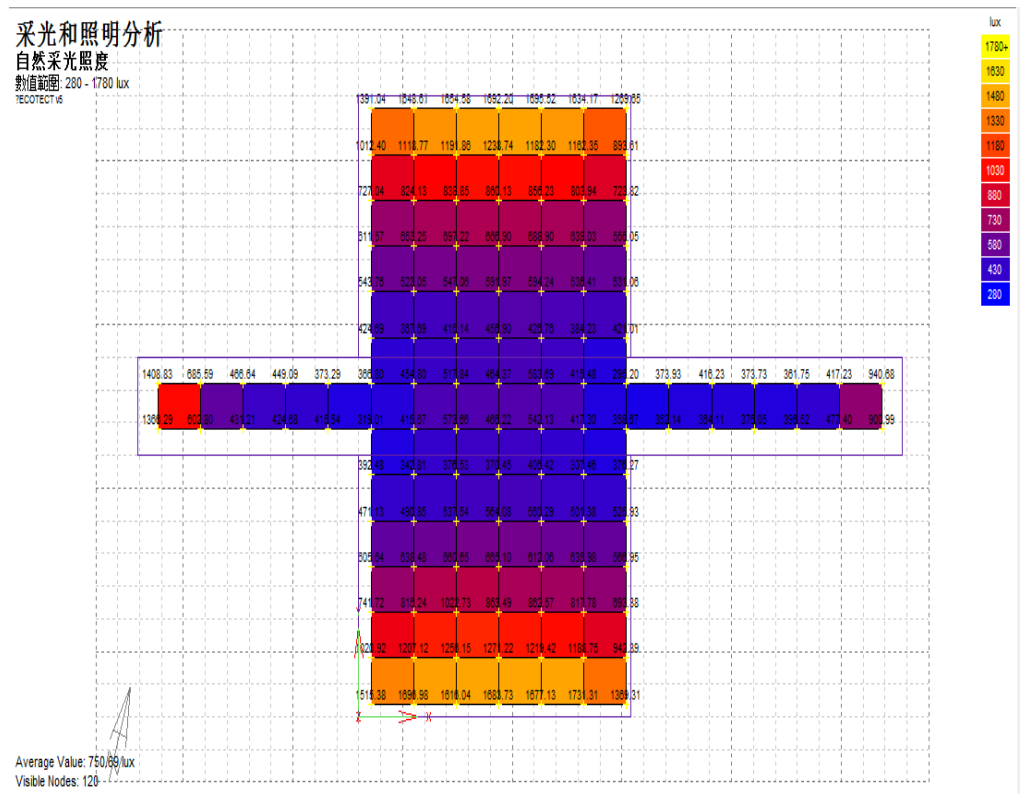

Fig.1.Distribution of Natural Illumination Before Reconstruction

\section{Application of BIM Technology in the Operation Stage}

Building energy consumption management system through BIM technology can be used for monitoring and managing the use of energy of every management unit and reflecting the data of energy consumption. Retrofitting buildings based on BIM technology can realize the resource-conservation and control the cost to a greater extent to achieve the maximum energy-efficiency during the process of renovating existing buildings.

\section{Proper Skills Applied to the Greening Transformation of Building Envelope Proper Skills Applied to Roof Reconstruction}

Roof, in summer, is a position with the strongest solar radiation . Considering energy-saving reconstruction on roofs, the first choice is cooling and heat insulation, and the second is roof insulation, like adopting planting roof, adding insulating layer, building overhead roof, etc.

(1) Planting Roof

Planting roof uses the transpiration of plants to increase evaporative heat dissipation, and it's efficient to reduce the internal surface temperature of the roof. Turf humus, perlite and vermiculite are commonly used for planting roof in Jiangsu. The thickness of overlaying soil must be restricted by the requirements. Bamboos, woods, engineering plastics and PVC can be used as the materials of the container of planted layer to reduce the weight. Perennial herb, creeping plants and dwarf shrub with shallow roots can be planted on roofs which are heat and wind-resisting and tolerant to drought and poor land. Sedum lineare, sedum sarmentosum, solenostemon scutellarioides, forsythia, dayflower and ophiopogon japonicus can be adopted as soil in Nanjing area. Depending on different loading levels and plant configuration of roofs, the height of plant layer can be fixed. In order to improve the waterproofness of roof, portland pozzolan cement with a thickness of $1.5-2.0 \mathrm{~cm}$ can be added to the original waterproof layer for soil-covered planting. ${ }^{3} \mathrm{~A}$ common structure of planting roof is given as an example, shown in fig. 2 . 


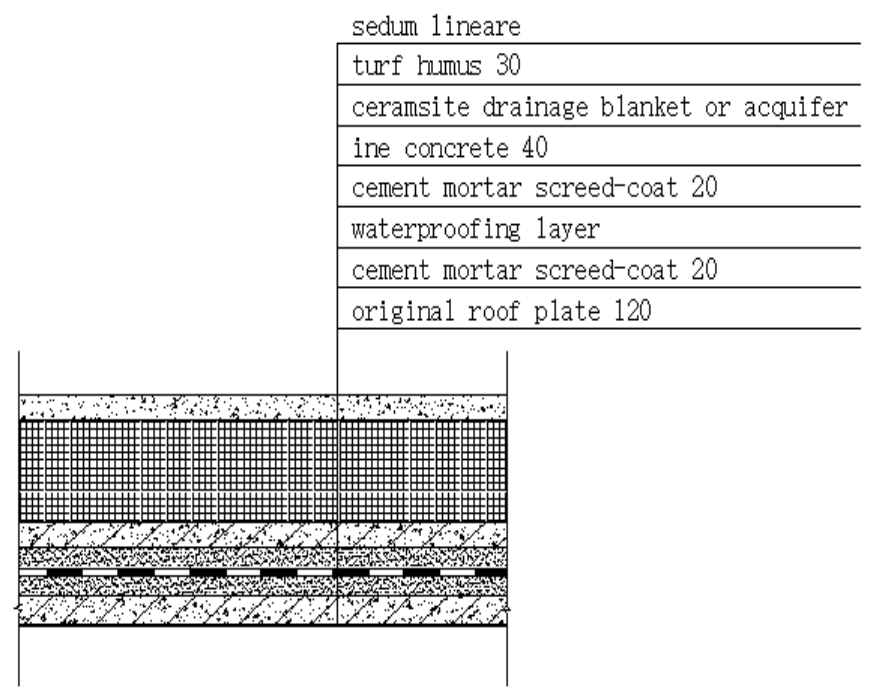

Fig.2.The Structure of Planting Roof (painted by author)

(2) Adding Insulating Layer

Add insulating layer to the original roof. The inverted insulating roof is to put the insulating layer on the waterproof layer, and this can not only prevent internal condensation of the insulating layer, but also protect the waterproof layer well, in addition, the durability of roof structure will be improved as well. Fig. 3 is one kind of the structure of inverted insulating roof. In China, the insulation materials for inverted insulating roof are mainly foam glass, squeezed polystyrene foam board, polyethylene foam board, etc.

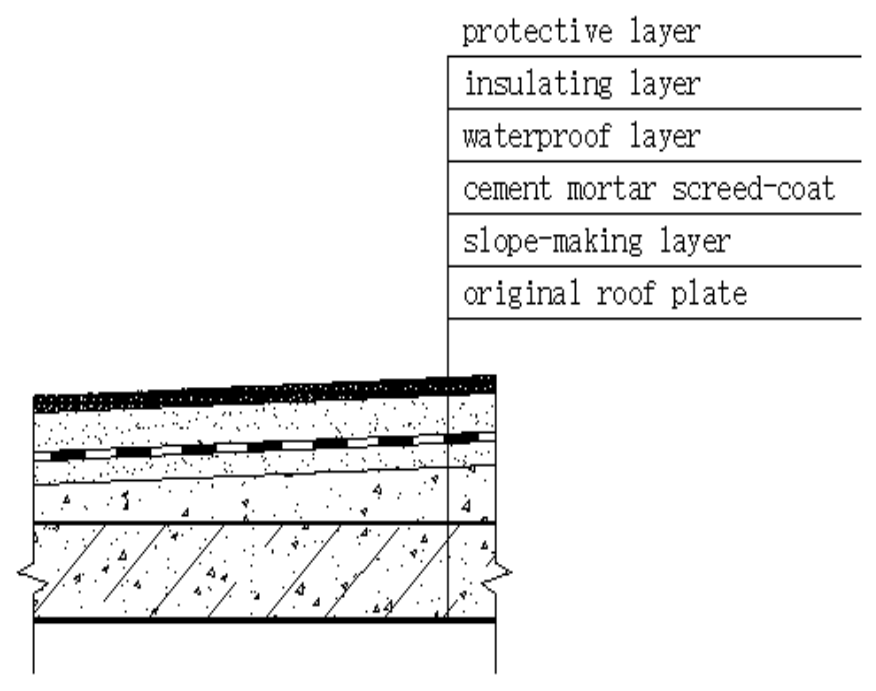

Fig.3.The Structure of Inverted Insulating Roof ( painted by author)

(3) Overhead Roof

Adding insulating layer and ventilation and heat-insulation layer to the original roof is to prevent the cracks of concrete layers when it is under the action of thermal stress. we provide an example of the structure of overhead roof ,as shown in fig.4.Building overhead roof can not only insulate the heat, but also lengthen the service life of 


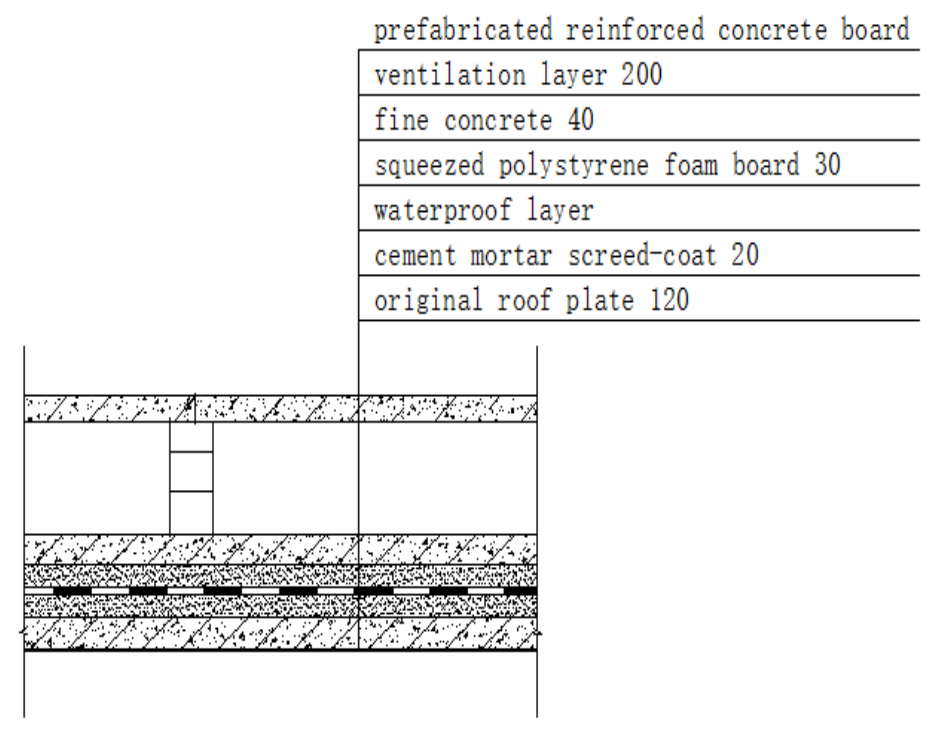

roof.

Fig.4.The Structure of Overhead Roof (painted by author)

\section{Appropriate Technologies for Reconstructions of Exterior Walls}

The exterior walls, which often cover a large area in the campus buildings, are important components of building enclosures. The heat loss of the exterior walls accounts for the largest proportion in the total heat loss of building enclosures. Therefore, there's a big potential to reconstruct the exterior walls for energy conservation. Thermal insulation system of exterior walls includes external wall thermal insulation, internal wall thermal insulation and the interlayer thermal insulation. External wall thermal insulation technology is commonly used for reconstruction of exterior walls. The external wall thermal insulation technologies which are suitable for technology promotion in Jiangsu: EPS plates thin plaster external wall thermal insulation technology, the XPS plates thin plastering exterior wall thermal insulation technology and PUR plates thin plaster external wall thermal insulation technology.

(1)EPS plates thin plaster external wall thermal insulation technology

EPS (expanded polystyrene) plates thin plaster external wall thermal insulation system is made of EPS plate insulation layer, a thin plaster layer and decorative coating. This system has advantages including small thermal conductivity, excellent waterproof performance and good weather fastness. However, it is prone to coming off when combined with heavier decorative materials because of its light weight and low mechanical strength. Therefore, only elastic coating is used as its decorative coating in this system.

(2) XPS plates thin plastering exterior wall thermal insulation system

XPS (extruded polystyrene) plates thin plaster external wall thermal insulation system, mainly made from polystyrene resin and copolymer, are rigid foam plastic plates with closed-cell structure through heating and extrusion molding technology. The system has extremely efficient heat preservation and prominent waterproof performance. Its disadvantages are lack of flexibility and prone to cracking. What's more, it demands higher construction technique and cost.

(3) The PUR plates thin plaster external wall thermal insulation system

PUR (polyurethane rigid foam) plates thin plastering exterior wall thermal insulation system is a new exterior wall thermal insulation system with great integrated performance. It is composed of PUR insulation layer, a thin surface layer and decorative coating. Its advantages are as follows: outstanding thermal insulation properties, strong heat resistance and high mechanical strength. The disadvantages are higher price and high water absorption rate. 


\section{Appropriate technologies for reconstruction of exterior windows}

In view of the characteristics of the teaching buildings, windows cover a large area in the exterior walls. The heat lost through windows and doors accounts for more than $50 \%$ of the heating and air conditioning energy consumption of the whole building, so exterior windows are weak links for heat preservation ,thermal insulation and energy conservation. Therefore, the reconstruction of exterior windows is a key point of the green transformation of the whole buildings.

For the energy conservation of the exterior windows, we should take following three aspects into consideration: the materials of window frame, glass and air tightness.

(1) Choosing the window frame materials with small thermal resistance. Window frame materials with small heat transfer coefficient are efficient in heat preservation and thermal insulation .The following two kinds of energy-saving window frame materials can be used. (1) energy-saving heat insulation aluminum alloy window frame uses non-metallic materials to make aluminum alloy materials insulated. It has many features such as high strength, thermal insulation, sound insulation, airtight, high watertight performance, long service life and so on. (2) FRP window frames is a new type of energy-saving window frame in recent years with the characteristics of light weight, high strength, not easily deformed, aging resistance, corrosion resistance and so on. As heat transfer coefficient of this type of the window is small, the exterior windows will have great thermal insulation performance when they are combined with hollow glass or low-radiation hollow glass.

(2) Replacing energy-saving glass. According to statistics, the total calories lost through glass accounts for around $80 \%$. Using the energy-saving glass can reduce the energy consumption caused by solar radiation through refraction of the glass itself. This kind of glass can be divided into the following three types: hollow glass, low emissivity coated glass and heat-reflective glass with thin film. If economic condition permits, you can choose double-layer hollow glass because its thermal insulation property is much better.

(3) Improving the air tightness of exterior windows. Gas-tight strips can be added to the original exterior windows in order to improve the air tightness of windows. You can select rubber strips, plastic strips, or rubber and plastic strips.

If the condition allows, you can use the exterior windows with good thermal performance and install the mobile shading device in order to achieve an ideal effect of energy conservation.

\section{Application of Renewable Resources in Greening transformation}

\section{Solar Energy}

Solar energy mainly uses photo voltaic technology with solar thermal power supplemented by. It focuses on installing solar water heaters in the colleges which have demands for hot water. Economic efficiency and environmental benefits should be considered as well as design ideas and environmental conditions when using photo voltaic technology. It sets solar panels indoors or outdoors for lighting, fan operating in the buildings and so on.

\section{Geothermal Energy}

The usage of geothermal energy is greatly affected by geology, earth surface and groundwater resources. Regional differences are obvious. The methods should be selected by specific cases. The methods includes earth source heat pump system, groundwater source heat pump system, surface water source heat pump system, etc.

According to my survey, solar energy has applied in some colleges in Jiangsu province, however, the utilization of other renewable resources is still low which has something to do with economic and technical conditions. In the long run, the usage of renewable resources in college buildings remains great potential. 


\section{Application of Energy-saving Management in Existing Buildings Energy-saving Behavior}

Energy-saving behavior is a new concept of energy conservation. College aims to train qualified talents to meet the needs of the country, and college students are undertaking significant historic mission. Letting students become practitioners and leaders of energy conservation and environmental protection will push forward the construction of resource-saving and environment-friendly society, achieving the result of get twice the result with half the effort. ${ }^{(4)}$

\section{Operating Management for Saving Energy}

According to a survey, there are ever-burning lamps, water dripping as well as uninterrupted operation of fans or air-conditioners in summer in many colleges. The core of operating management for saving energy is the establishment of the regulatory system, to get real-time data of energy consumption, and realize remote transmission and centralized management. Classification measurement is adopted by small buildings with low energy consumption. Itemized measurement is adopted by large buildings with high energy consumption which are equipped with centralized air- conditioning and central heating system. Special measurement is for labs with huge energy consumption.

\section{Application in Building Practice}

A college teaching building integrates teaching, experiment, office, scientific research with five layers of frame structure and north-south exposure, and it has been used for more than ten years. Some structures and devices are aging in the building. The main problems are: (1). The heat insulation of walls, roofs, doors and windows is poor and solar radiation is strong from the south and west. The indoor thermal environment is far from satisfactory. (2). The device against heat insulation of roofs is aging, and only curtains have been used for keeping off sun from the south and west. (3). The phenomenon of power and water consumption is severe, and ever-burning lamps and cooling system idling do exist because of lacking of monitoring platform for energy-saving.

As the layout and orientation of this teaching building have been fixed and short of the funds, the following transformation plans have been proposed:

Reconstruction in Building Envelope: (1) Double-layer windows will be put to use which add a layer of low emissivity (Low-E) glass to the original glass . (2) Creepers can be planted on the walls facing west. (3) Fixed external shading device can be used for south-facing windows. (4) Insulating material like expanded polystyrene(EPS) can be adopted for outer walls. (5) Planted roofs will be employed which use turf humus as soil for planting sedum lineare.

Application of Renewable Energy: (1) Rainwater gathering tank can be installed for gathering rain to flush toilets and watering the plants on the roof. (2) Solar panels can be set on the roof or outer walls for generating electricity, and it will be used for partial illumination and operation of cooling fan.

Application of Energy-saving Technology: (1) Install the numerical meter, water meter, etc. (2) Install LED lamps controlled by voice technology and water-saving faucet. (3) establish platforms for managing energy data to strengthen the management of energy. (4) Itemized measurement can be used for system refining of air-conditioning heating, illumination, etc. (5) Special measurement is for labs and research building with huge energy consumption.

Energy-saving Behavior: (1) Creating atmosphere of energy-saving in campus through environmental publicity and education. (2) Energy-saving behavior can be regarded as a part of assessment of teachers and students. 


\section{Conclusions}

Still we have much to do to construct green college campuses in Jiangsu province. Skills on greening transformation should be based on local conditions. Inheritance and protection of the traditional culture of schools should be payed attention to as well when reforming campus buildings. In a word, everything serves for helping constructing strong, rich, beautiful and civilized "New Jiangsu".

\section{References}

(1)CSUS/GBC 04 - 2013, Evaluation Criterion for Green Campus[S]. Shanghai:

Chinese Society for Urban Studies (CSUS) -- Speciality Commission for Green and Energy-Saving Building, Tongji University, China Academy of Building Research, 2013.

(2) WU Xiaoyan. Application Research of Existing Building Renovation Based on BIM Technology [J]. Construction Technology,2016,12:57-59.

(3) Li Minghui and Yang Difang. Performance Study on Wall and Roofing Materials in Energy-saving Buildings of Nanjing Area [J]. Energy Conservation in Building, 2008,06:31-34.

(4) JIANG Chunlei. Analysis on the Current Situation and Countermeasure of Energy Conservation and Emission Reduction in Colleges [J]. Education Research of Shanghai University of Engineering Sciences,2013,04:51-53. 